\author{
M. José De Córdoba Serrano \\ Research, Development and \\ Cultural Promotion Department of \\ Artecittà International Foundation \& UGR. \\ Mjdecordoba@ugr.es; info@artecitta.es \\ mjdecor@terra.es
}

\title{
Why study synesthesia? What can that teach us about ourselves?
}

\begin{abstract}
This essay describes the results of the author's projects of studying synaesthesia in Spain (University of Granada). It outlines several surveys of potential synaesthetes and possible relations of synaesthesia, creativity and types of "sensory representation"/ intelligence. The author provides her own original definition of "natural synaesthesia" as multi-modal thinking actualized through diffuse perception and polyphonic attention. Such an understanding emphasises the importance of constant philosophical reconsideration of synaesthesia and an interdisciplinary approach to researching the phenomenon. One of the major conclusions made in this essay is that synaesthesia is embedded in the multiple and multilevel processes of the unconscious that constitute both thinking and creativity. Which in turn might mean that perception could be explained through synesthesia and not the other way around, with subsequent revision of the theories of cognitive processes in psychology and neurosciences. The described results lay the foundations for the author's synaesthesia-based applied methodologies in art education that are aimed to raise awareness of unusual perception among potential synaesthetes and enhance holistic creative thinking of the students through the multi-sensory aspects that they can further include into their own projects.
\end{abstract}

Keywords: synaesthesia; ideaesthesia; survey; applied methodologies; art education; multi-modal thinking; sensory representations.

There are many reasons to think that, during these last few years of study on synesthesia, a remarkable majority of the sciences known today have 
taken an interest in this phenomenon. Lately, not only neuroscience and psychology have turned to synesthesia, but also new technologies, the science of education, and the Visual Arts. There are also emerging studies, such as the neuroesthetics or neuromarketing, that have become very attracted to this phenomenon. All of these studies have led to reconsidering a lot of the concepts that were immovable, certain and determined; these are ones related to knowledge, thinking, the psychology of perception, cognition, language, learning, intelligence and others, tottering many theories of perception and cognitive development.

Recalling Ortega y Gasset in What is philosophy? (1960), I also maintain that the latest scientific ideas, hesitating, show themselves to be unsafe and poorly founded; in this case, we are referring not to the knowledge of "being" and the need to fill our "ignorance", in general, by our lack of "knowledge" of what is "being" in philosophy (whatever it is as it relates "to being"). In this paper I am making an attempt at contemplating something as difficult as synesthetic perception and its true being, its true essence and existence.

If synesthesia is a genuine perception, and it does function in compliance with the laws of such, as so many contemporary researchers in the field of cognitive psychology and neuroscience have shown in these last 25 years (e.g., Spector and Maurer 2009; Asher et al. 2006, 2009), there is, however, not a theory that fully explains it. To mention just a few schools of thought: neither associationism, which sees the perception as a "mosaic of sensations," nor Gestalt theory that, paradoxically, could have explained it better because of its holistic approach, equipped with all its laws, anyway, overlooked the syncretic undifferentiated vision, when we perceive the whole of something so diffuse, with polyphonic attention. This is a fact that I have always pointed out since my early research, and which is closely related to attention (conscious and unconscious). Regarding this, Gestalt theory has also failed to explain synesthetic perceptions.

This syncretistic vision, in addition to diffuse attention, is very much related to the human creative capacity, which is very closely linked to intuition and the unconscious. Indeed, the Gestalt explains optical illusions very well. And if everything that we perceive is an "illusion", and everything that we "know" about the world is what we see/receive, would synesthesia also be an illusion? Although synesthesia seems to be a much more complex perceptive/cognitive phenomenon.

Notably, some previous researchers in neuroscience come to the conclusion that even the colors do not exist and are wonderful perceptions that our brain creates as "quale": 
What this means is that our more simple perceptions have made us what we are. More than that, and this is truly amazing, the color remember, which does not exist - has molded the physical fabric of the world and has been the core of the human culture. Due to our intimate relationship with color, people have been asking for centuries if you see what I see. Our response would reveal not only a lot about how our brain works, but also about who we are as individuals, as well as societies [...]. Are we being deceived? Or do we all see the world in different ways. In fact, we have no other choice, given that our experiences are different. But none of it looks like it is. In that sense, we all live deceived: What each of us sees is a meaning derived from our individual stories and shared. This reality, perhaps more than anything else, provides an irrefutable argument to celebrate diversity, rather than to settle for fear. And that is liberating, because knowing it gives you the freedom to take responsibility for their future perceptions about this and other things.

(http://www.bbc.co.uk/mundo/noticias/2011/08/110809_colores_ ver.shtml)

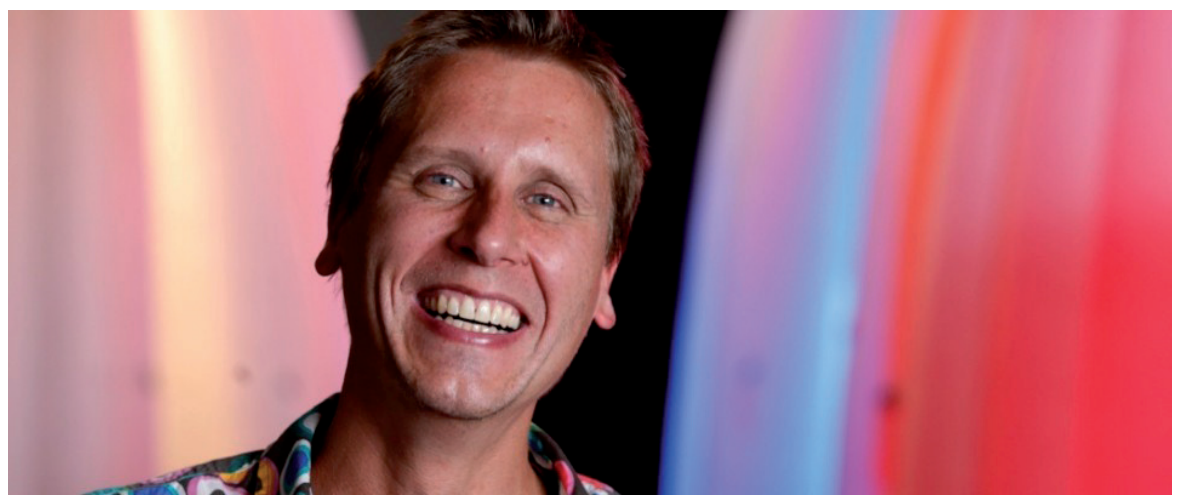

Image 1. Beau Lotto is one of several scientists who depart from the question that so many of us have: do you see what I see?

Later on, in the middle of the $20^{\text {th }}$ century, Denis pointed out that part of non-verbal knowledge consists not only in images, but also implies synesthesia, motor skills, the corporeal and affectivity. An image is not a passive layer of psychological reality, but an active construction (Denis 1979). So, if this is considered true, we could say that perhaps our perception could be explained through synesthesia and not the other way around. This prompts another allusion to Ortega y Gasset stating that man discovers time after time, below that system of views, the primordial chaos, and steps back 
only to feel shipwrecked. "As a result, he returns to philosophy, to build a being more firm" (Ortega y Gasset 1960).

I felt like starting my essay with a nod to philosophy, the mother of all sciences, because one of my conclusions is that, necessarily, just as science and art should never have separated, Philosophy has much to say in the study/ science of synesthesia, regarding the way Cognition goes hand in hand with synesthesia (for which here I use the term natural) to construct the world we perceive.

In contrast, vivid synesthesia, which might also be manifested as ideaesthesia at its least, should be conceived as low-level conceptual synesthesia or of an unconscious/subconscious character, and gained in our evolutionary and cognitive development. Although there are new hypotheses about whether synesthesia, as it is generally called, is to be actually called ideaesthesia, term proposed by Danko Nikolić (2012), but, in my opinion, this notion is best to be reserved for low-level conceptual or unconscious/ subconscious synesthesia and, in this respect, I will use this term as such from now on.

The questions raised here are pertinent questions, as Socrates would say, and my questions, rightly or wrongly constructed, I say with all humility, have led me to the conclusions I will present at the end of this paper. However, I must relate what the steps were in my research, which I began in the late ' $80 \mathrm{~s}$, and continued between turns, reconsidering my concepts and perspective. This has given me a better understanding that the dimensions my study encompasses are so tremendous, that it necessitates an interdisciplinary approach.

My research focuses on the phenomenon of synesthesia as natural perception, that is likely to be mitigated during cognitive development and acquiring the regularities of the "sensory world" (also mediated by cultural systems and stimulated a little by educational methodology), due to specialization of the senses (here I agree with Spector and Maurer 2009). But it can be active and ongoing throughout life, for various reasons, in a small percentage of the population, perhaps by inheritance, as per the theories of geneticists, or by a stimulating environment facilitating its sustenance, enhancing creative thinking in people engaged in the arts or creativity in general.

The results of my study are applied in the field of education, which, as we know, is also interested in methodologies that enhance the overall abilities of students, especially if they belong to the field of Fine Arts. This is precisely what our objective is: to enhance the overall abilities of the student through the multi-sensory. 
Since 2006, I have conducted general surveys of potential synesthetes among students of the University of Granada, with the intention of finding a correlation between creativity and synesthesia, while also seeking to reveal common features amongst synesthetic personalities. The results have been presented at various international congresses held in Almería and Granada (Andalusia, Spain), which have been held every two years since 2005, thanks to the International Foundation Artecittà and the universities of Granada and Almeria.

I wish to review some of the results that were presented at the last congress of 2012, held at the University of Almeria, as well as their educational applications at the University of Granada, in the Faculty of Fine Arts, both at the graduate and post-graduate levels, because they are proving to be effective and enlightening.

We start with the first results obtained in the surveys from 2006 to 2009 . These data reinforce the idea that synesthesia is very real perceptionrelated sensory and cognitive processes that might be tentatively considered as "multi-modal thinking". The connection between perception-creativity, language and synesthesia-was unveiled as the main thing to study in art education. The population group was from 18 to 36 years old, a small group which could not provide reliable results, for this reason we decided to increase the survey pool to get a larger number of possible synesthetes for studying and testing, in order to acquire other data and verify the supposed characteristics of synesthete personalities, types of synesthesia, its impact on learning, formation of concepts and its potential to advance creative development. This was also intended to generate new methodologies or teaching approaches through synesthesia that can enable and enhance holistic creative thinking.

Then I will present a summary of the work outlined in the Fourth International Congress of Synaesthesia, Science and Art 2012, which can be found in full in the published proceedings book and other literature.

$[\mathrm{W}]$ ith the sharing of results and new approaches, new lines of research open; retaking early studies and reviewing the literature found from the late nineteenth and early twentieth centuries, it is curious that scientific approaches already existed on this condition but were not well known to this day. There were even authors, very little known, such as Mercante (1910), who was concerned with teaching methods and experimental psychology which were closely related to synesthesia. Already at that time, he wrote about verbocromía and synesthesia cases found among his students. 
Therefore, what we are doing now is reviving studies started centuries ago (the above is just one example); and now we can understand better thanks to new technological tools and the tendency to recognize the communion and interdisciplinary collaboration between the different "sciences" as the best way to reveal the mysteries that confine the brain when it perceives the world and when one "thinks", mixing one's senses or sensory forces.

"Revisions and new research contributions concerning synesthesia also get echoed in the press and audiovisual media in making documentaries, newspaper articles, in book publishing, and organization of courses and workshops on 'synesthesia, art and creativity' that the International Foundation Artecittà organizes, getting the attention of large numbers of people, such as teachers, departments, centers of art." This activity leads to many people in the general public recognizing themselves as synesthetes, so the percentage of them increases each year. In addition, it leads to the realization that this study is very necessary in any field of education, not only in neuroscience, experimental psychology or other cognitive sciences, or in the artistic / musical or literary fields.

In 2009, as a lecturer at the Department of Drawing at the University of Granada, I proposed an innovation project aimed to implement educational knowledge of synesthesia and creativity, introducing new methodological units with a view to tapping into potential originality and possible synesthetic abilities among students in the Faculty of Fine Arts. The project was implemented in collaboration with other teachers both at the Department of Experimental Psychology and Drawing and Educational Sciences of the University of Granada. Our initiative of acquainting our students with and informing them about current studies regarding synesthesia, and having them participate in the exploration generated such an interest that it has even become the subject of research in many of their final course projects or Masters' theses, the latter being mostly on drawing production and popularization. Some of these students were discovered to be synesthetes and used this information to investigate themselves and their artistic production." Today, they are already achieving success in their own artistic synesthetic productions based on synesthesia.

I think "natural synesthesia", possibly, comes into play in each of the perceptual processes, cognitive processes and generated concepts about visible reality, which is felt and expressed. There are sufficient reasons, I can say, that certain unconscious perceptual processes are intimately linked to synesthetic experiences or constitute the source of many of the so-called lowintensity synesthesias and ideaesthesias or experiences similar to synesthesia. We now know that ideaesthesia is very common; one can say that $99 \%$ of the 
population experience it in its most unconscious form. The concepts we form throughout our development and learning are steeped in multiple sensations of color, shape, taste, touch and emotions, being as a "whole" indivisible. We can recall the studies on the relationships between sound, color, form, image, and concepts, conducted by Michael Haverkamp (2009), or similar ideas outlined by myself in the early years of my research about synesthesia, in 2005 (not to mention, of course, the well-known educational methods developed at the Bauhaus). This leads us to think directly of processes of development of our multiple intelligences and teaching methods that, however, were not without gaps and errors, which makes them short of being conducive to creating innovative and creative minds. It seems that now there is a more serious interest since, more and more, it is known how we think, how we build and how we create and generate our "ideas".

We do know that there are genetic components that may cause one to "inherit" the possibility of having vivid synesthesia, so to speak, in a conscious way, or we get to keep those early childhood interconnections between different brain areas, and that there is evidence about the relationship between creativity and synesthesia. "In one of the recently published articles summarising what we know of synesthesia and characteristics of people with synesthesia, authored by V. Ramachandran and D. Brang, we find the following passage:

However, the nature of the link between synesthesia and creativity (including metaphor) remains elusive given that synesthesia involves arbitrarily connecting two unrelated things (e.g., color and number), whereas there is a non- arbitrary conceptual connection between, say, Juliet and the sun (of Romeo and Juliet). One potential solution to this problem comes from realizing that any given word has only a finite set of associations (e.g., the sun is warm, nurturing, radiant, bright, etc.). The overlapping region among halos of associations between two words (e.g., Juliet and the sun; both are radiant, warm, and nurturing) - the basis of metaphorexists in all of us but is larger and stronger in synesthesia as a result of the cross-activation gene; in this formulation synesthesia is not synonymous with metaphor, but only that the gene which produces synesthesia confers a propensity towards metaphor. While the link between synesthesia and creativity has received remarkable interest over the last decade, research has not yet directly demonstrated any causal relationship between the two and so the argument, at this point, remains seductive and compelling but not conclusive. 
But what interests me in this review is part of the conclusions that the authors come to in their work that we ourselves discovered during the development of our teaching innovation project:

[...] In summary, synesthesia is a highly heritable phenomenon that is associated with numerous benefits to cognitive processing, potentially underscoring a basis for why this condition has survived evolutionary pressures. Research into synesthesia is now passing its bicentennial anniversary in science, and understanding both the mechanisms underlying the phenomenon and the reasons for its selection are finally at a point in which synesthesia can inform our understanding of cognitive and perceptual processes in the general population. To appropriately understand this condition and its relation to normal cognition will require both technically and intellectually diverse contributions from all areas of biology. In sum, this research suggests that synesthesia, far from being a "fringe" phenomenon as formerly believed (or that it is purely "conceptual" or associative in nature), can give us vital clues toward understanding some of the physiological mechanisms underlying some of the most elusive yet cherished aspects of the human mind (Brang and Ramachandran 2011).

The question then would be: "Is synesthesia a sensory phenomenon, a cognitive-conceptual phenomenon, or both? And also, are there limits that separate the experiences of synesthesia and non-synesthetic experiences? And if so, are these limits clear or fuzzy?", to quote Professor Larry Marks' similar ideas (2012/2009).

In the surveys we have conducted, we have found that there is an important component in such perceptions of vivid synesthesia that may have been previously overlooked: consciousness and attention.

Why do the participants in these courses and surveys realize these perceptions and mixing of senses only when they have been informed of them? Were they not aware of them before that? Would they not have paid enough attention so far? Or is it that they "imagine" them now, once informed?

Evidence of the prevalence in the general population of common associations between shapes, colors and sounds is very strong, which suggests that these associations / mixtures or linkages among concepts, sounds, shapes and colors are produced from an unconscious level, since cognitive processes and language development were already present long before all that development in a collective unconscious, since man is man. 
This is demonstrated in some of the experiments on primates (similar to human relations) who display correspondences between color and sound, as we can see, for example, in the research by Ludwig et al. (2011).

This is quite similar to what we found in experiments conducted in 2000 on the same topic concerning matches between sound and color in synesthetic and non-synesthetic people, that was presented at the Second International Congress on Synaesthesia, Science \& Art, Granada, 2007 ( $\mathrm{M}^{\mathrm{a}}$ José De Córdoba Serrano 2007).

We carry out activities and workshops for students of Fine Arts, during which we are trying to find answers, to observe and analyze. In these activities, we consider this type of crossing of the senses - we can call them "natural" or unconscious - attracting the interest of students and participants in their own perceptual multimodal intersensorial processes, allowing usage in creative artistic developments.

We also report on our investigations, studies and theories of synesthesia. We propose participatory workshops: related to the topics of music, painting, and the synesthetic / kinesthetic body as vehicles to explore their creative capabilities. And we gave the students three tests: a simple poll on synesthesia, one on creative originality and another on neuro-linguistic programming (NLP).

According to the results we obtained and analyzed, we can clearly differentiate between those who experience vivid synesthesia and others who have ideaesthesias or conceptual synesthesia. We sometimes find projective synesthesia, but rarely, in a small percentage.

For those who have sound/color and music/color types of synesthesia, and for the rest to take advantage of the course, "Draw the music: incomplete map of sound memories", (a course offered by the Department of Drawing at the University of Granada in collaboration with the University of Cadiz, who organized the Spanish music festivals of Cadiz of which the course is a part), we have participating students focus on their audio / visual (colors and shapes) perceptions through drawing. This experience brought about other activities, research and very interesting artistic productions that helped reveal how students exploit and develop their artistic potentials spurred by these new methodologies that are based on synesthesia and creativity. 


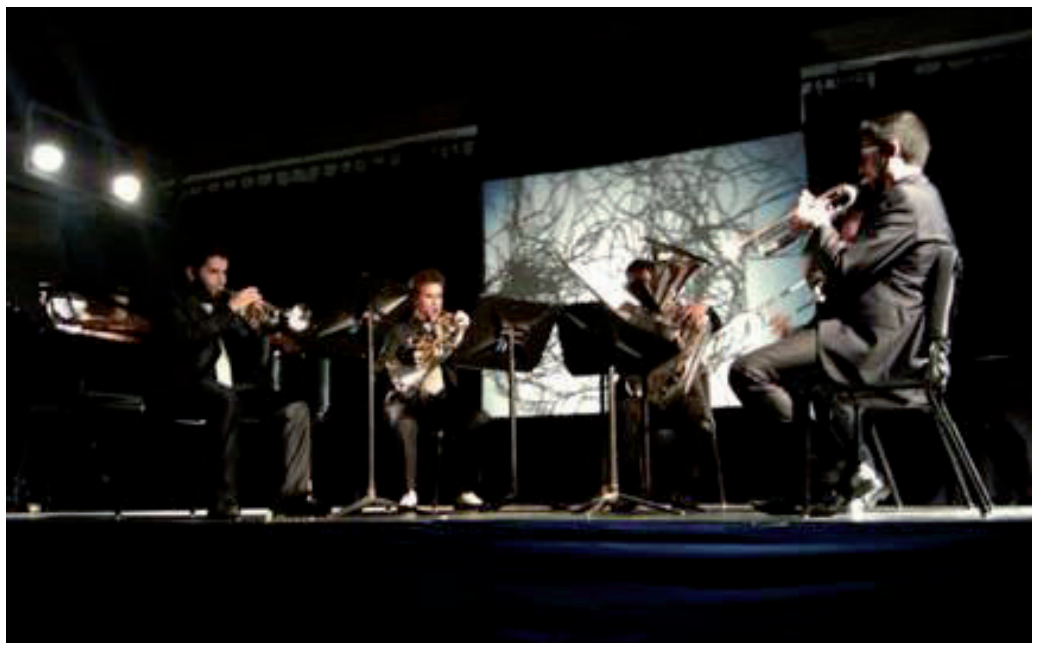

Image 2. IX Spanish Music Festival of Cadiz, 20011. "White Night". Painting Live overhead

From these experiences arise groups of student / artists developing multidisciplinary activities using the concept synesthesia for performances, as a "total work of art", where dance, music, live painting, and creative improvisations are the components of these works with a common link: synesthesia.

In our surveys of possible synesthetes, we considered the following issues and reflections:

\section{Preliminary issues:}

1. How can we know if creativity, intelligence, and training of the individual can really be facilitated by this condition, depending on whether he or she is or is not a synesthete?;

2. What relation does the concept of "multiple intelligences" have with synesthesia?;

3. What about the originality / creativity or NLP?

\section{Reflections:}

1. A pluralistic view of the mind, intelligence conceived as dynamic, as the ability to solve problems or make products that are valuable in a particular cultural context. 
2. However, the propagation of homogenization of intelligence types in students through uniform mass education is a problem that does not allow the recognition of the diversity of human cognitive potentials whereby each individual has his or her own way of organizing, coding, interpreting and appropriating (apprehending) information.

Gardner (1983/2011) and the followers of his theory believe that "human beings have evolved to exhibit several intelligences and not to draw variously on one flexible intelligence" (Gardner 2011, p. xxx).

To answer these questions, we need to elaborate on the study of synesthetes and those with signs of experiencing synesthesia, further analyzing the results we obtained. We are in this work to develop the fundamentals of this science, which still needs the collaboration of researchers from other areas of knowledge so that, once the results of these studies, analysis and research are pooled together, we can draw more reliable conclusions applicable to the field of teaching.

Our goals are:

- To define the concept of synesthesia in a rigorously scientific manner and reveal its impact on the study of the basic principles of psychology (perceptual development, attention, cognition, memory, creativity, language, personality) and its application in training teachers.

- To apply these data about the peculiarities found in the different aspects of synesthesia in relation to each (interdisciplinary) area of knowledge that include the following:

- Neurology

- Psychology

- Psychiatry.

- Linguistics

- Education

- Literature

- Art

- Music

\section{Outline: Fieldwork}

- Simple survey test of possible synesthetes.

- Relationship with originality / creativity (Finke test) and its system of sensory representation (NLP).

The type of test used regarding creativity is based on studies by Roland Finke using creative visualization, mental imagery, and originality. (In our 
experiment, we considered this as comparable to imaginative invention). We presented simple geometric shapes, letters or numbers which must be mentally combined to form a recognizable figure, which should also be named via a name / term defining it. We measured the time it takes to complete the test with at least one minute allowed for each combination of forms. We also asked the participants for their assessment, more or less, as to the degree they liked the outcome (a score of 5 equals the highest score, a 1 the lowest score).

We analyzed nine groups of respondents (in Granada, 500 individuals). We consider as valid for analysis a total of 316 people, of which 168 are possible synesthetes and 51 show less indicative signs of the condition. The ages are between 17 and 50 years.

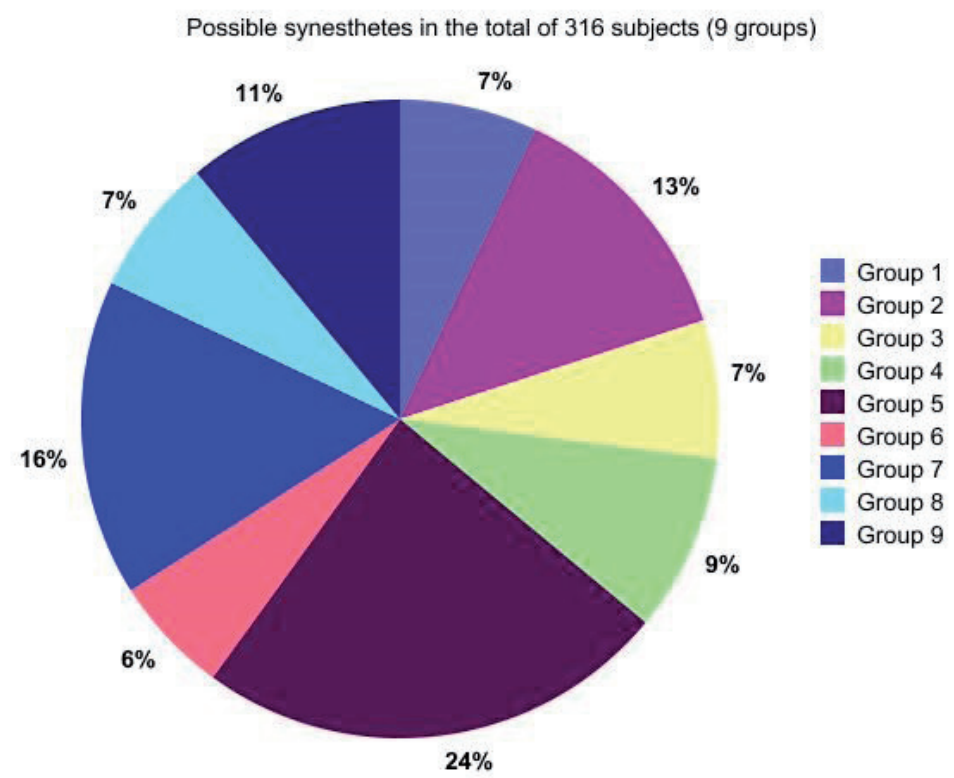

Graph 1. Percentages of possible synesthetes in 9 groups (a total of 316 people)

The groups are students from the Faculty of Fine Arts of the University of Granada, the School of Communication Studies ESCO, the Toledo School for the Arts, and those participating in the summer courses of the years 2008, 2010 and 2011. 
The identified types are:

Table1. Results as per types of synesthesia

\section{Types}

total

Grapheme/color

Letter/number/gender/personality

Days/months/color

Hours/days/space configuration

Music/sound/color

Speech/taste

other
34

66

61

44

68

24

7

As can be seen, there is a high percentage with the possibility of having vivid synesthesia, and if we add to this percentage (33.6\%) that of those presenting evidence $(10.2 \%)$, the total number rises even further. This is a lot, if we compare this with other studies from the United States or England, where only $4 \%$ of the population is demonstrated to be possible synesthetes (Simner et al. 2006). The most common category found in our study is also music / sound to color, followed by gender- / personality-based and spatiotemporal synesthesias.

As we continued to investigate the most common sound to color type, we devised a computer "online" application, a basic upgradeable test, for this category, adding texture and voice. This was an attempt to find possible Spanish-speaking synesthetes. This year, we have received test results of about 1000 people from Spanish-speaking countries (Venezuela, Mexico, Ecuador, and Spain, among others) identifying themselves as having this type of synesthesia. These participants will be tested again to make sure their answers / choices are consistent. If such is the case, we can conclude that their "associations or correspondences" are real. 


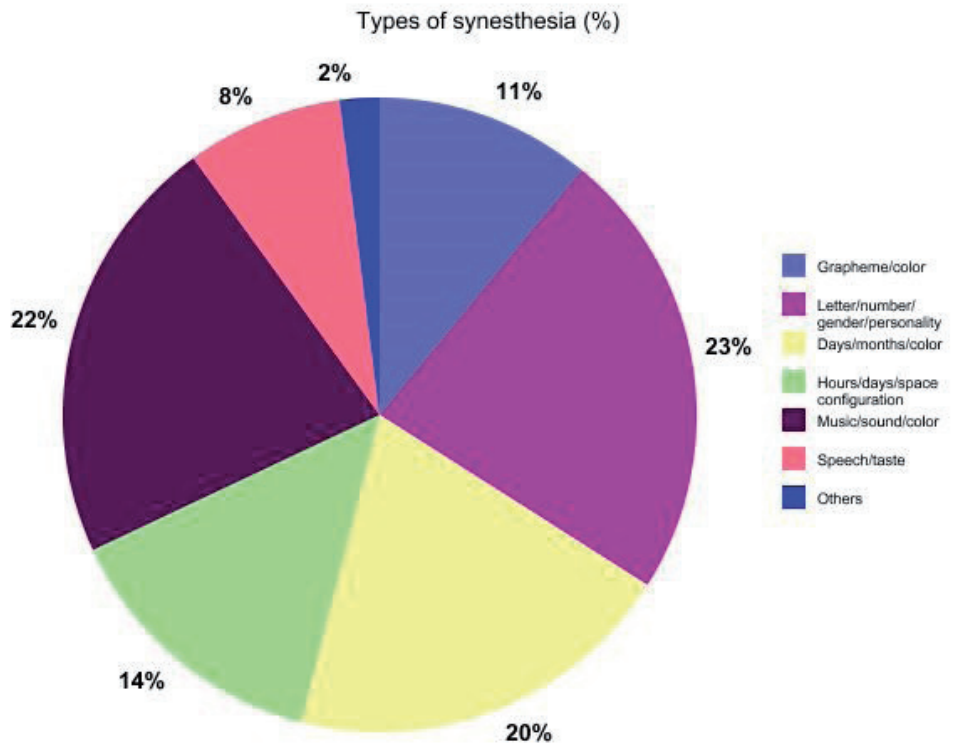

Graph 2. Percentages of types of synesthesia discovered in the 9 investigated groups

NLP sensory representations in possible synesthetes $(n=103)$

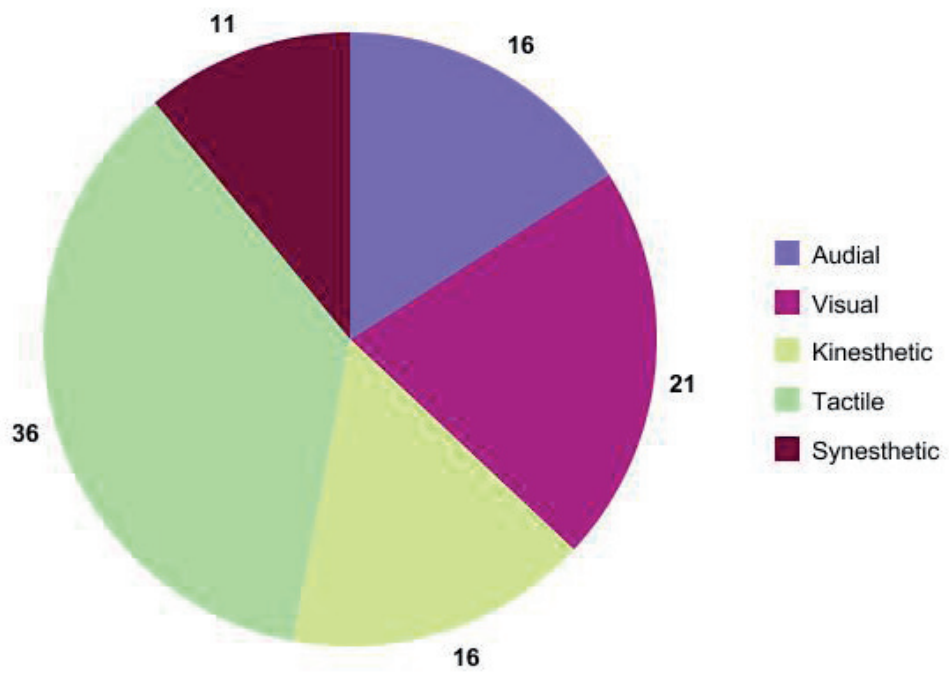

Graph 3. Percentages of NLP found in 9 groups 
We are still searching for a system of sensory representation of synesthesia types found in $11 \%$ of the potential synesthetes in the present study. There is a possibility that they just use synesthesia-related language.

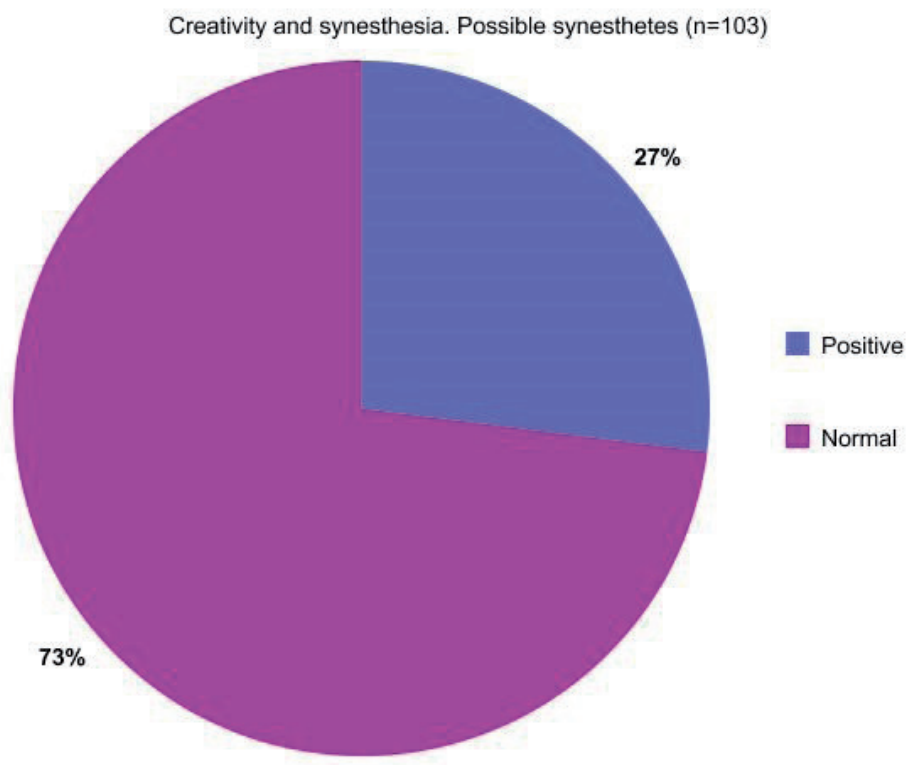

Graph 4. Percentages regarding synesthesia and creativity

Table 2. Synesthesia, sensory representations in the NLP systems and creativity

\begin{tabular}{|l|l|r|r|r|l|l|r|r|r|r|}
\hline $\begin{array}{l}\text { Synesthesia + NLP+ } \\
\text { Creativity } \\
\text { Total number }\end{array}$ & NLP & Group7 & Group 8 & Group9 & $\begin{array}{l}\text { Total } \\
\text { number }\end{array}$ & CREATIVITY & Group 7 & Group 8 & Group 9 & $\begin{array}{l}\text { Total } \\
\text { number }\end{array}$ \\
\hline 103 & Audial & 3 & 1 & 0 & 4 & POSITIVE & 4 & 1 & 4 & 9 \\
\hline & Visual & 4 & & 1 & 5 & NORMAL & 11 & 4 & 9 & 24 \\
\hline & Kinesth. & 3 & 4 & 7 & 14 & & & & & \\
\hline & Tactile & 7 & 1 & 4 & 12 & & & & & \\
\hline & Synesth. & 2 & 1 & 4 & 7 & & & & & \\
\hline
\end{tabular}

Regarding the results of our research into the relations between originality / creativity and synesthesia, $27 \%$ of those surveyed had a greater capacity than the remaining participants, but $73 \%$ had the same results as the creative non-synesthetes. These data reinforce the results of our polls in the previous years: people who showed signs of having synesthesia are all creative but not to an extent exceeding creative non-synesthetes, although we found no 
synesthetes presenting a low level of creativity. Therefore, we can conclude that both psychological traits share some common brain processing systems.

\section{Conclusions}

We have seen throughout this summary of activities, workshops, courses and surveys that the population of possible synesthetes is greater than we could imagine, perhaps because it is conceptual synesthesia that is the most common type, or it is characteristically close to ideaesthesia. The vivid or high level synesthesias are also shown to be at a higher percentage than expected.

Making students and other participants conscious of such experiences (aware of possible sensory correspondences as a method to activate their creative possibilities) has proven to be a very productive tool. Beyond the importance of discovering that synesthesia is not so "rare", we find it more interesting that educational methodologies which have as their core the concept of synesthesia awaken skills and attitudes "hidden" in the students. They are motivated and, therefore, embark on developing their multiple intelligences. With regard to the students of Fine Arts, from different courses and levels, they respond with enthusiasm and curiosity, which helps them improve their artistic production. We believe that innovation in teaching methodologies applicable to the overall development of the student is important.

Currently, we continue collecting data to analyze in depth, contrasting these with those data collected in previous years. In my opinion, the unconscious acquisition and cognitive processes that are already automatic could explain some of the very common conceptual synesthesias and ideaesthesias. The characteristics attributed to synesthetic personalities are still not too clear.

Regarding the teaching innovation project and my experience teaching drawing, where I conduct a course on synesthesia ("Scientific approach to the interdisciplinary study of synesthesia"), within the scope of drawing, production and distribution, the results have been optimal. Students get to expand their field of vision and conduct research projects on synesthesia and art, some at the highest level. At the same time, they introduce other lines of research in design, advertising and synesthesia, or other areas of expertise, such as in teaching of artistic expression and education. All approaches generate new knowledge and help to open up new resources that enhance and clarify aspects of empowerment and optimization of creative and innovative capacities, both in teachers and in students. For all these reasons, we continue 
our studies and surveys in the hope of forming a "corpus" and foundation of the "science" of synesthesia.

In 2005, we set off building up - and we have actually built the theoretic aspects of - a mathematical model of synesthetic sensory processes, towards which it is necessary to continue the survey of possible synesthetes in different social spheres and of different ages. This project in which we are currently engaged, will allow us to pool a larger group and number of individuals who will be able to implement the necessary studies. These brief notes about research which we want to bring to fruition may give a slightly better sense of the importance and size of the investigation into the natural condition that we are just beginning to understand. Of course, it is philosophy that provides an unrestrained perspective to discuss the "being" of synesthesia.

\section{References}

Asher, Julian E., Michael R. F. Aitken, Nasr Farooqi, Sameer Kurmani and Simon Baron-Cohen. 2006. "Diagnosing and phenotyping visual synaesthesia: a preliminary evaluation of the revised test of genuineness (TOG-R)." Cortex 42.2: 137-146.

Asher, Julian E., Janine A. Lamb, Denise Brocklebank, Jean-Baptiste Cazier, Elena Maestrini, Laura Addis, Mallika Sen, Simon Baron-Cohen and Anthony P. Monaco. 2009. "A whole-genome scan and fine-mapping linkage study of auditory-visual synesthesia reveals evidence of linkage to chromosomes 2q24, 5q33, 6p12, and 12p12." American Journal of Human Genetics 84.2: 279-285.

BBC Mundo. 2011. Los colores no existen. http://www.bbc.co.uk/mundo/ noticias/2011/08/110809_colores_ver.shtml

Brang, David and Vilayanur S. Ramachandran. 2011. "Survival of the synesthesia gene: Why do people hear colors and taste words?" PLoS Biology 9.11: e1001205.

De Córdoba Serrano, Maria José. 2007. "La investigación interdisciplinar sobre la sinestesia: desarrollo y objetivos / The Interdisciplinary Research on synaesthesia: development and objectives." Actas del II Congreso Internacional de Sinestesia, Ciencia y Arte. Granada.

Denis, Michel. 1979. Les images mentales. [Spanish translation: Las imagenes mentales; Madrid: Siglo Veintiuno de Espana, 1984]. Paris: Presses Universitaires de France.

Gardner, Howard. 1983. Frames of Mind. The Theory of Multiple Intelligences. Basic Books. 
Haverkamp, Michael. 2009. Look at that sound. In Actas del III Congreso Internacional de Sinestesia, Ciencia y Arte. Granada.

Ludwig, Vera U., Ikuma Adachi and Tetsuro Matsuzawa. 2011. "Visuoauditory mappings between high luminance and high pitch are shared by chimpanzees (Pan troglodytes) and humans." PNAS 108: 20661-20665.

Marks, Lawrence. 2012/2009. La sinestesia por el espectro. In Maria Josè De Cordoba and Dina Riccò (eds.). Sinestesia/Synesthesia: Los Fundamentos Teóricos, Artísticos y Cientificos [Theoretical, artistic and scientific foundations]. Granada: Ediciones Fundación Internacional Artecittà.

Mercante, Victor. 1910. La Verbocromia: Contribución al estudio de las facultadas expresivas. Madrid: Jarro.

Nikolić, Danko. 2012. Is synaesthesia actually ideaestesia? An inquiry into the nature of the phenomenon. In Proceedings of the Third International Congress on Synaesthesia, Science \& Art. Almeria, Spain.

Ortega y Gasset, José. 1960. What is philosophy? trans. by Mildred Adams. New York: W.W. Norton.

Simner, Julia, Catherine Mulvenna, Noam Sagiv, Elias Tsakanikos, Sarah A. Witherby, Christine Fraser, Kirsten Scott and Jamie Ward. 2006. "Synaesthesia: the prevalence of atypical cross-modal experiences. Perception 35: 1024-1033.

Spector, Ferrinne and Daphne Maurer. 2009. "Synesthesia: A new approach to understanding the development of perception." Developmental Psychology 45.1: 175-189. 